- four programmes (Rhodes, Greece; Fuka-Matrouh, Egypt; Sfax, Tunesia; Duvace-Vlore, Albania) will be concluded by 1994-1997;

- two programmes (Algeria, Morocco) will be carried out.

To manage actions aimed not only at protecting the environment but also at stimulating efficiency in economy and social equity, of which sustainable development consists, is an unprecedentedly hard task. Networking governmental and non governmental bodies is necessary but, in its turn, requires unexperimented management patterns. This is the Mediterranean challenge.

\section{Med Coast '93 by Erdan Ozhan}

The first international Conference on the Mediterranean Coastal Environment, MEDCOAST 93, took place during 2-5 November 1993, in Antalya, Turkey. This conference, organized jointly by the Turkish National Committee on Coastal Zone Management and Middle East Technical University, starts a new conference series to focus on the environmental and scientific issues of the Mediterranean and the Black Sea, as well as the integrated management of their coastal and sea resources.

The MEDCOAST 93 Conference was sponsored by 18 international and national organizations including the Council of Europe, UNEP Mediterranean Action Plan, UNDP, International Coastal and Ocean Organization (ICO), and the Association EUROCOAST. The conference topics which were broad enough to cover almost all relevant issues, were presented in three groups, namely: "Physical, ecological and conservations issues", "Integrated coastal and sea resource management and development", and "Coastal engineering, modeling and data management". About 120 abstracts were selected for oral and poster presentations, and a significant number of proposals had to be rejected due to program limitations. About 90 papers were received before the deadline for being including in the conference proceedings (2 volumes).

MEDCOAST 93 was a lively and stimulating meeting. 140 professionals from 26 countries, representing various disciplines and affiliations, participated in the conference. A Permanent International Committee and Secretariat for MEDCOAST conference was set up. Its main responsibilites are the scientific management of future conferences and securing international sponsorship. The next conference, MEDCOAST 95, is scheduled to take place in Barcelona, Spain, during the last week of October, 1995.

Parallel to the conferences, a second dimension of the MEDCOAST initiative in the area of human resource development, is underway. In the context the MEDCAMPUS program of the European Community, a proposal named the "Network MEDCOAST" has been approved for financial support. This project proposes to develop a full graduate prgram and a 4 week long certificate program on the theme of "Coastal Zone Management in the Mediterranean". Both these programs, to be conducted in English, will be run by an international faculty, and will be open to students from the riparian countries of the Mediterranean and the Black Sea. The first certificate program is scheduled to take place partly in Ankara and in a locality on the Turkish coastline during the late summer of 1994.

The third dimension of the MEDCOAST initiative is networking among the professional groups, both scientific and environmental, of the riparian countries towards information exchange and collaborative research and monitoring on the state of coastal and sea environment, and on use patterns of resources. This challenging dimension which will require signicant levels of international sponsorship, is at a development stage.

All three dimensions of the MEDCOAST project will complement the new priorities and programs of the Mediterranean Action Plan which are expected to be developed along the principles of the UNCED, eg Agenda 21, MEDCOAST Project has the capability of contributing significantly to the future role of MAP by providing very much needed scientific and professional support to national and international policies, if a platform for valuable mutual interactions between MAP and MEDCOAST can be established.

Address: ICCOPS, Via dell'Acciaio, 139, 16152 - Genova (Italia). Te1.: +39-10-6514000, Fax: +39-10-6503801, Email. iccops@ice.ge.cnt.

Editorial Committee:

Maurizio Arcari (University of Parma), Stefano Belfiore (ICCOPS Secretary-General), Maria Giuseppina Lucia (University of Genoa), Maria Clara Maffei (University of Parma) Tullio Scovazzi, Editor-in-chief (University of Genoa), Adalberto Vallega (ICCOPS President)

\title{
Asian Urbanization Conference Information
}

The Fourth Asian Urbanization Conference was held in Taipeh, Taiwan from January 2, 1994 through January 9, 1994. Grand Hotel was the venue. Over 60 participants, 45 of whom were from outside Taiwan, participated in the conference. Twelve countries were represented. Three dozen papers were presented on Asian Urbanization and they were from various disciplines; geography, architecture, history, economics, planning, public administration and sociology. The host was the National Taiwan University and the principal local organizers were Professors Nora Chang and David Chiang. The Asian Studies Center of the Michigan State University, East Lansing and its director Dr. Jack Williams also helped organize the conference.

The Asian Urbanization Conference is held every third year under the auspices of the Asian Urban Research Association (AURA) permanently headquartered in the Geography and Planning Department of The University of Akron. Dr. F. J. Costa, Dr. A.K. Dutt, Dr. L.J.C. Ma and Dr. A. G. Noble are the Executive Committee members of the AURA. The first conference was held in Akron in 1985, the second in Nanjing, China in 1988 and the third in Delhi, India in 1991.

The Fifth Asian Urbanization Conference is scheduled to be held in London at the end of August 1997. School of Oriental and Asian Studies (SOAS) of the University of London will be the local host.

The chief local organizer of the 5 th conference is:

Professor Graham Chapman, Head

Geography Department

School of Oriental and Asian Studies

University of London

Thomhaugh Street

Russell Square

London WC1H 0XG

Telephone: 071-637-2388

Telex: 262433 W 6876

Fax: 071-463-3844 